\title{
Molecular Cloning and Functional Analysis of the Gene Encoding 3-hydroxy-3-methylglutaryl Coenzyme A Reductase from Hazel (Corylus avellana L. Gasaway)
}

\author{
Yechun Wang', Binhui Guo ${ }^{1}$, Fei Zhang ${ }^{1}$, Hongyan Yao ${ }^{1}$, Zhiqi Miao ${ }^{1}$ and Kexuan Tang ${ }^{1,2, *}$ \\ ${ }^{1}$ Plant Biotechnology Research Center, School of Agriculture and Biology, School of Life Science and Technology, \\ Fudan-SJTU-Nottingham Plant Biotechnology R\&D Center, Shanghai Jiao Tong University, Shanghai 200030, PR China \\ ${ }^{2}$ State Key Laboratory of Genetic Engineering, School of Life Sciences, Morgan-Tan International Center for Life Sciences, \\ Fudan-SJTU-Nottingham Plant Biotechnology R\&D Center, Fudan University, Shanghai 200433, PR China
}

Received 1 May 2007, Accepted 9 June 2007

The enzyme 3-hydroxy-3-methylglutaryl-CoA reductase (HMGR; EC1.1.1.34) catalyzes the first committed step of isoprenoids biosynthesis in MVA pathway. Here we report for the first time the cloning and characterization of a fulllength cDNA encoding HMGR (designated as CgHMGR, GenBank accession number EF206343) from hazel (Corylus avellana L. Gasaway), a taxol-producing plant species. The full-length cDNA of $\mathrm{CgHMGR}$ was 2064 bp containing a 1704-bp ORF encoding 567 amino acids. Bioinformatic analyses revealed that the deduced CgHMGR had extensive homology with other plant HMGRs and contained two transmembrane domains and a catalytic domain. The predicted 3-D model of CgHMGR had a typical spatial structure of HMGRs. Southern blot analysis indicated that CgHMGR belonged to a small gene family. Expression analysis revealed that $\mathrm{Cg} H M G R$ expressed high in roots, and low in leaves and stems, and the expression of CgHMGR could be up-regulated by methyl jasmonate (MeJA). The functional color assay in Escherichia coli showed that CgHMGR could accelerate the biosynthesis of $\beta$-carotene, indicating that CgHMGR encoded a functional protein. The cloning, characterization and functional analysis of $\mathrm{CgHMGR}$ gene will enable us to further

Database Accession No: EF206343

\begin{abstract}
Abbreviations: HMGR, 3-hydroxy-3-methylglutaryl coenzyme A reductase; MEP, 2C-methyl-D-erythritol 4-phosphate; MVA, mevalonic acid; MeJA, methyl-jasmonate; PCR, Polymerase chain reaction; RACE, rapid amplification of cDNA ends; RT-PCR, reverse transcriptase-polymerase chain reaction.
\end{abstract}

*To whom correspondence should be addressed.

Tel: 86-21-62932002; Fax: 86-21-62824073

E-mail: kxtang1@yahoo.com or kxtang1@163.com understand the role of CgHMGR involved in taxol biosynthetic pathway in $C$. avellana at molecular level.

Keywords: Hazel, 3-hydroxy-3-methylglutaryl-CoA reductase (HMGR), RACE, Taxol biosynthesis

\section{Introduction}

Taxol, one of the best selling anti-cancer drugs worldwide, was originally isolated with extremely low yield from the bark of Taxus brevifolia (Wani et al., 1971), which is one of the slowest growing trees in the world. It is evident that the harvesting of Taxus bark is not a viable long-term option for taxol production in industry. Therefore it is necessary and important to find alternative sources to produce taxol, one of the most expensive anti-cancer drugs. In 1998, an exciting discovery was announced that taxol could be extracted from the angiosperm Corylus avellana L. by Hoffman and her colleagues, and later by other groups (Hoffman et al., 1998; Boone et al., 2000). Very recently, it has been further confirmed that hazel cell cultures could produce taxol and taxanes under controlled conditions (Bestoso et al., 2006). Although the amount of taxol found in hazel was about onetenth that of the yew, hazel was a widely grown species and grows much faster than yew. Therefore, hazel is a new potential source for taxol production in the future (Service, 2000). In addition, knowledge of the biosynthetic pathway is important for improving the production of this drug. Taxol synthesis can be regulated by overexpressing the key ratelimiting enzyme genes of taxol biosynthetic pathway (Eisenreich et al., 1996; Jennewein et al., 2004). Isolation and analysis of genes encoding key enzymes involved in the taxol biosynthetic pathway would be helpful to enhance taxol production through 
taxol bioengineering in the near future.

In plants, it is well known that there are two distinct isoprenoids biosynthesis pathways, the plastidic 2C-methylD-erythritol 4-phosphate (MEP) pathway and the cytosolic mevalonic acid (MVA) pathway (Rohmer et al., 1993). But the two pathways are not separated absolutely. In some extents, there are some forms of crosstalk between them (Laule et al., 2003). As diterpenes, taxol is formed in the isoprenoid pathway. It has been demonstrated that the precursor of taxol is biologically synthesized from both MVA pathway and MEP pathway (Lansing et al., 1991; Zamir et al., 1992; Eisenreich et al., 1996; Palazon et al., 2003). The 3hydroxy-3-methylglutaryl-CoA reductase (HMGR; EC1.1.1.34) catalyzes the first committed step in MVA pathway for biosynthesis of isoprenoids (Chappell, 1995), and earlier studies suggested that Taxus produced high rates of radioactivelylabelled taxol when supplied with labeled mevalonate, demonstrating that taxol was produced from mevalonate, which was catalyzed by HMGR (Lansing et al., 1991; Zamir et al., 1992). Therefore, HMGR probably acts as one of the key regulatory enzymes for taxol biosynthesis in MVA pathway. Up to now, there has been no report on the cloning of HMGR gene from hazel.

In this paper, we report for the first time the molecular cloning and characterization of $C g H M G R$ gene from hazel by RACE technique. The expression profiles of the $C g H M G R$ and its biological function in $E$. coli were also investigated.

\section{Materials and Methods}

Plant materials and growth conditions. The taxol-producing hazel (Corylus avellana L. Gasaway), kindly provided by Drs. Shawn A. Mehlenbacher and Bruce R. Bartlett at Oregon State University, USA, was used as the research material. For surface sterilization, hazel seeds were soaked in $75 \%(\mathrm{v} / \mathrm{v})$ ethanol for $1 \mathrm{~min}$ and then rinsed 3 times with sterile distilled water. Hazel embryos were pelt out and then germinated on solid Murashige and Skoog (1962) medium (pH 5.8) with $3 \%(\mathrm{w} / \mathrm{v})$ sucrose and grown in darkness at $25^{\circ} \mathrm{C}$ for two weeks. After two weeks, the germinated seedlings were transferred to soil and grown in a greenhouse at $27 \pm 1^{\circ} \mathrm{C}$ with $16 \mathrm{~h}$ light and $8 \mathrm{~h}$ dark photoperiod.

Plant treatments. Leaves from four-week-old seedlings were sprayed with $2 \mathrm{mM}$ MeJA (dissolved in $0.1 \%$ ethanol and water). Meanwhile, leaves were also sprayed with only $0.1 \%$ ethanol without any elicitors as the control. The treated and control plant leaves were harvested respectively at $0,6,16,24,36,48,72,96$, and $108 \mathrm{~h}$ after treatment for RNA extraction. All experiments were carried out in triplicates.

DNA and RNA isolation. The four-leaf stage seedlings were used for genomic DNA and RNA isolation in the experiments. Genomic DNA and total RNA of hazel were extracted using the modified CTAB method (Paterson et al., 1993; Jaakola et al., 2001). The quality and concentration of the extracted DNA and RNA were checked by agarose gel electrophoresis and rationed by Nucleic
Acid Protein Analyzer (DU-640, Beckman). The DNA and RNA samples were stored at $-20^{\circ} \mathrm{C}$ and $-70^{\circ} \mathrm{C}$ respectively prior to use.

Isolation of $\boldsymbol{C g H M G R}$ core cDNA fragment. Two degenerate oligonucleotide primers, HMGRF (5-GG(G/C/T)GATGC(A/T/C) ATGGG(G/A)ATGAA(C/T)ATG-3) and HMGRR (5-AC(A/T/C) GT(A/C/G)CC(A/C)ACCTCAAT(N)GA(A/T/G)GGCAT-3), were designed and synthesized based on the conserved amino acid sequence regions of several plant HMGRs. RT-PCR was performed to amplify the core fragment of $C g H M G R$ gene with the two degenerate primers according to the protocol of One Step RNA PCR Kit (TaKaRa). The PCR program was carried out under the following condition: $50 \mathrm{~min}$ at $50^{\circ} \mathrm{C}, 94^{\circ} \mathrm{C}$ for $2 \mathrm{~min}$ followed by 30 cycles of amplification ( $30 \mathrm{~s}$ of denaturation at $94^{\circ} \mathrm{C}, 30 \mathrm{~s}$ of annealing at $58^{\circ} \mathrm{C}, 1 \mathrm{~min}$ of extension at $72^{\circ} \mathrm{C}$ ). After the final cycle, the amplification was extended for $7 \mathrm{~min}$ at $72^{\circ} \mathrm{C}$. The amplified products were subcloned into pMD18-T vector (TaKaRa, Japan) and then sequenced by ABI 3730 Sequencer (Perkin-Elmer, USA). Subsequently, the core fragment was used to design and synthesize gene-specific primers to clone the $3^{\prime}$ and 5 ' fragments of $C g H M G R$ by RACE.

3' and 5' RACE and the full-length cDNA cloning of $\boldsymbol{C g} \boldsymbol{H} M G R$. A SMART ${ }^{\mathrm{TM}}$ RACE cDNA Amplification Kit (Clontech) was used to isolate the 3'-and 5'-ends of $C g H M G R$ cDNA. The 3'-ready and 5 '-ready cDNA libraries were synthesized by reversely transcribing $1 \mu \mathrm{g}$ of total RNA with 3'-CDS primer A and 5'-CDS primer, respectively. For 3' RACE of $C g H M G R$, the first round PCR was performed to amplify the 3'-end cDNA with the 3'-gene-specific primer CgHMGR 3-1 (5'-GTTGTTTGCGAGGCTCTCATAAG-3') and UPM (Universal Primer A Mix, provided by the kit), and 3'RACE ready cDNA was used as template. The PCR product diluted 20-fold was used as template for the nested PCR with CgHMGR 3-2 (3'-CAACATCGTCACTGCCATCTAC-3') and NUP (provided in the kit). For 5' RACE of $C g H M G R$, two gene-specific primers, CgHMGR 5-1 (5'-CTTATGAGAGCCTCGCAAACAAC-3') and CgHMGR 5-2 (5'-GGATGTTCTGGACGCCTTTGG-3'), were designed and synthesized according to the sequence of the obtained core fragment. The first round PCR was performed with primer CgHMGR 5-1 and UPM, and 5'-RACE ready cDNA was used as template. The PCR product diluted 20-fold was used as template for the nested PCR with CgHMGR 5-2 and NUP. An Advantage 2 PCR Kit (Clontech) was used in the first round and nested PCR amplification of 5'-end and 3'-end. The PCR program was used according to the protocol (SMART ${ }^{\mathrm{TM}}$ RACE cDNA Amplification Kit, user manual Clontech) with 25 cycles of amplification ( $30 \mathrm{~s}$ at $94^{\circ} \mathrm{C}, 30 \mathrm{~s}$ at $68^{\circ} \mathrm{C}, 1 \mathrm{~min}$ at $72^{\circ} \mathrm{C}$ ). Subsequently, the products were ligated into pMD18-T vector followed by sequencing. After aligning and assembling the sequences of the core fragment, 3' RACE and 5' RACE products, the full-length cDNA sequence of $C g H M G R$ gene was deduced and subsequently obtained by PCR using PCR primers CgHMGRCF (5'-GAAACAAAAACCCAAATCCACACACACA GTCAAC-3') and CgHMGRCR (5'-TACACAAAAGAATACAAC AAACAAACGGAT-3) with 5'-RACE-ready cDNA as template under the following condition: $3 \mathrm{~min}$ at $94^{\circ} \mathrm{C}$ followed by 35 cycles of amplification $\left(30 \mathrm{~s}\right.$ at $94^{\circ} \mathrm{C}, 30 \mathrm{~s}$ at $60^{\circ} \mathrm{C}, 140 \mathrm{~s}$ min at $72^{\circ} \mathrm{C}$ ), with an additional $7 \mathrm{~min}$ at $72^{\circ} \mathrm{C}$. The PCR products were purified, cloned into pMD18-T vector and sequenced. 

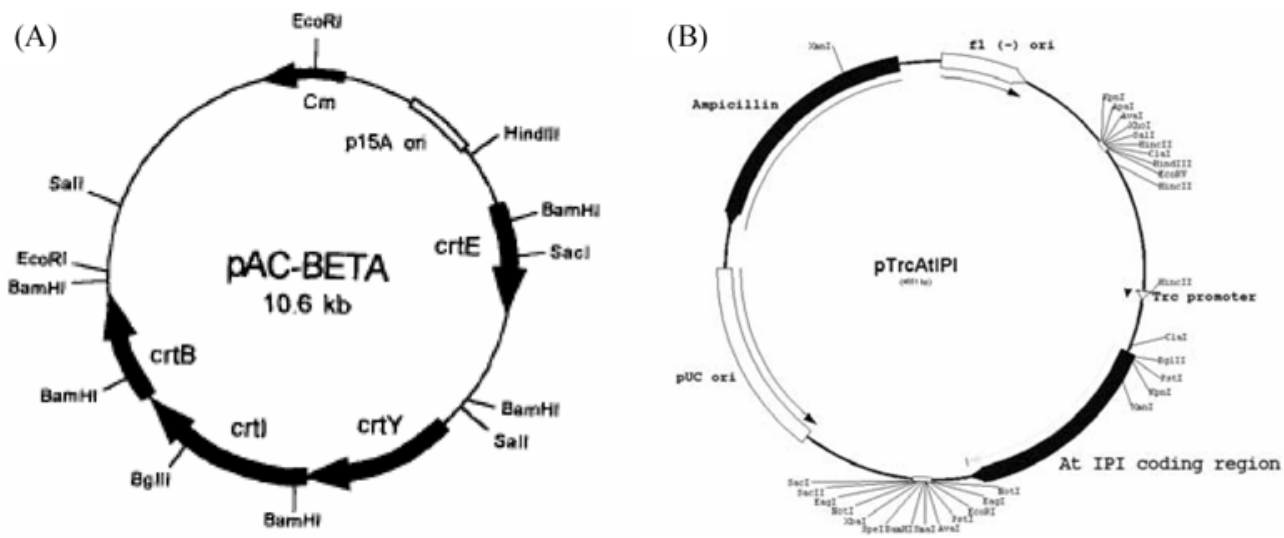

Fig. 1. Restriction maps of the function-testing plasmids pAC-BETA and pTrc-AtIPI. (A) The plasmid, pAC-BETA, contains all genes of the $\beta$-carotene synthesis including $c r t E, c r t B, c r t I$ and $c r t Y$, and also retains a chloramphenicol resistance gene. (B) The plasmid, pTrc-AtIPI, retains an ampicillin resistance gene and AtIPI.

Bioinformatic analyses. The sequence analysis of $C g H M G R$ was carried out online at the websites (http://www.ncbi.nlm.nih.gov and http://www.expasy.org). Vector NTI ${ }^{\mathrm{TM}}$ Suite 8 was used for sequence multi-alignment analysis. Homology-based structural modeling was accomplished by Swiss-Model (Schwede et al., 2003), and WebLab ViewerLite 4.0 was used for 3-D model display.

Southern blot analysis. Aliquots of hazel genomic DNA $(25 \mu \mathrm{g} /$ sample) were digested overnight at $37^{\circ} \mathrm{C}$ with $B g / I I, E c o R I$ and HindIII respectively, which did not cut within the CgHMGR cDNA region, electrophoresed in $0.8 \%$ agarose gel and transferred to Hybond $\mathrm{N}^{+}$membrane (Amersham Biosciences) according to the standard procedure. The 682 -bp probe was generated by PCR using the full-length sequence of $C g H M G R$ as template with primers HMGRSF (5'-AGGCTCCAGACCATCAAGTGCG-3') and HMGRSR (5'-CCAGAGCAGACATCAGAGACAG-3'), and then labeled by biotin using the random primer method (the Amersham Multiprime Labeling system). Southern blot analysis was carried out according to the manufacturer's protocols (Amersham Pharmacia). The hybridized signals were visualized by exposure to Fuji medical Xray film at room temperature for $2-3 \mathrm{~h}$.

RT-PCR analysis. Semi-quantitative RT-PCR was used to investigate the expression profiles of $C g H M G R$ in different tissues including roots, stems and leaves, as well as leaves under different treatment with $2 \mathrm{mM}$ MeJA as mentioned earlier. Total RNA was extracted from roots, stems, leaves and treated leaves respectively, followed by incubation with RNase-free DNase I at $37^{\circ} \mathrm{C}$ for 30 min according to the manufacturer's protocols (TaKaRa, Japan). Aliquots of total RNA $(1 \mu \mathrm{g} / \mathrm{sample})$ were used as templates in one-step RT-PCR with primers HMGRSF and HMGRSR. Meanwhile, two primers, 18SF (5'-AAGACCTACACCAAGCCCAA-3') and 18SR (5'-AA GTGAGCCCACACTTACCA-3'), were also used to amplify the house-keeping gene (18S rRNA gene) as an internal control. The template was reversely transcribed at $50^{\circ} \mathrm{C}$ for $50 \mathrm{~min}$ and denatured at $94^{\circ} \mathrm{C}$ for $2 \mathrm{~min}$, followed by 28 cycles of amplification $\left(94^{\circ} \mathrm{C}\right.$ for $30 \mathrm{~s}, 55^{\circ} \mathrm{C}$ for $30 \mathrm{~s}$ and $72^{\circ} \mathrm{C}$ for $1 \mathrm{~min}$ ) and by extension at $72^{\circ} \mathrm{C}$ for $7 \mathrm{~min}$. The products were separated on $1 \%$ agarose gel stained with ethidium bromide $(10 \mu \mathrm{g} / \mathrm{ml})$ and analyzed with Gene analysis software package (Gene Company, USA).

Functional analysis of CgHMGR in Escherichia coli. The plasmids pAC-BETA and pTrc-AtIPI, kindly provided by Francis X. Cunninham Jr at the Department of Cell Biology and Molecular Genetics, University of Maryland, USA, were used to investigate the biological function of $\mathrm{CgHMGR}$. The restriction maps of pACBETA and pTrc-AtIPI were shown in Fig. 1. The pAC-BETA contains all functional genes of the $\beta$-carotene synthesis including crtE (GGPP synthase), crtB (phytoene synthase), crtI (phytoene desaturase) and crtY (lycopene cyclase) genes (Misawa et al., 1995), and also retains a chloramphenicol resistance gene. The pTrc-AtIPI retains an ampicillin resistance gene and AtIPI gene. The E. coli strain TOP10 F' was used as the host strain to test the function of $\mathrm{CgHMGR}$. The experiment was performed as follows: the coding region of $C g H M G R$ was amplified by PCR using a pair of primers ORFHMGRF (5'-GAAGATCTATGGACGTACGCCG GCGATCGACC-3') and ORFHMGRR (5'-ATAAGAATGCGGCC GCTTAAGAGGAAACCTTGGAAACATC-3') containing BglII and NotI digesting sites. The PCR products were first fractionated on agarose gel and then purified and sequenced. After digesting both PCR fragment and pTrc-AtIPI with BgIII and NotI, the coding region of $C g H M G R$ was cloned into the empty vector pTrc to generate the plasmid pTrc-CgHMGR which was verified by sequencing. The $\mathrm{p}$ Trc-AtIPI was digested by Pst $\mathrm{I}$ and ligated by T4 DNA ligase as control. The vectors pTrc-CgHMGR and pACBETA were co-transformed into the $E$. coli TOP10 F'. Meanwhile, the vector pTrc and pAC-BETA were also co-transformed and the single vector pAC-BETA was transformed into the E. coli TOP 10 $\mathrm{F}^{\prime}$ as controls. Transformants were cultured on solid LB medium containing ampicillin $(150 \mathrm{mg} / \mathrm{L})$ and chloramphenicol $(50 \mathrm{mg} / \mathrm{L})$ at $37^{\circ} \mathrm{C}$ for $2 \mathrm{~d}$. The color of the transformants was as a visible marker to test the function of CgHMGR.

\section{Results and Discussion}

Generation of the full-length cDNA of $\mathrm{CgHMGR}$. The genes encoding HMGR have been cloned and characterized 


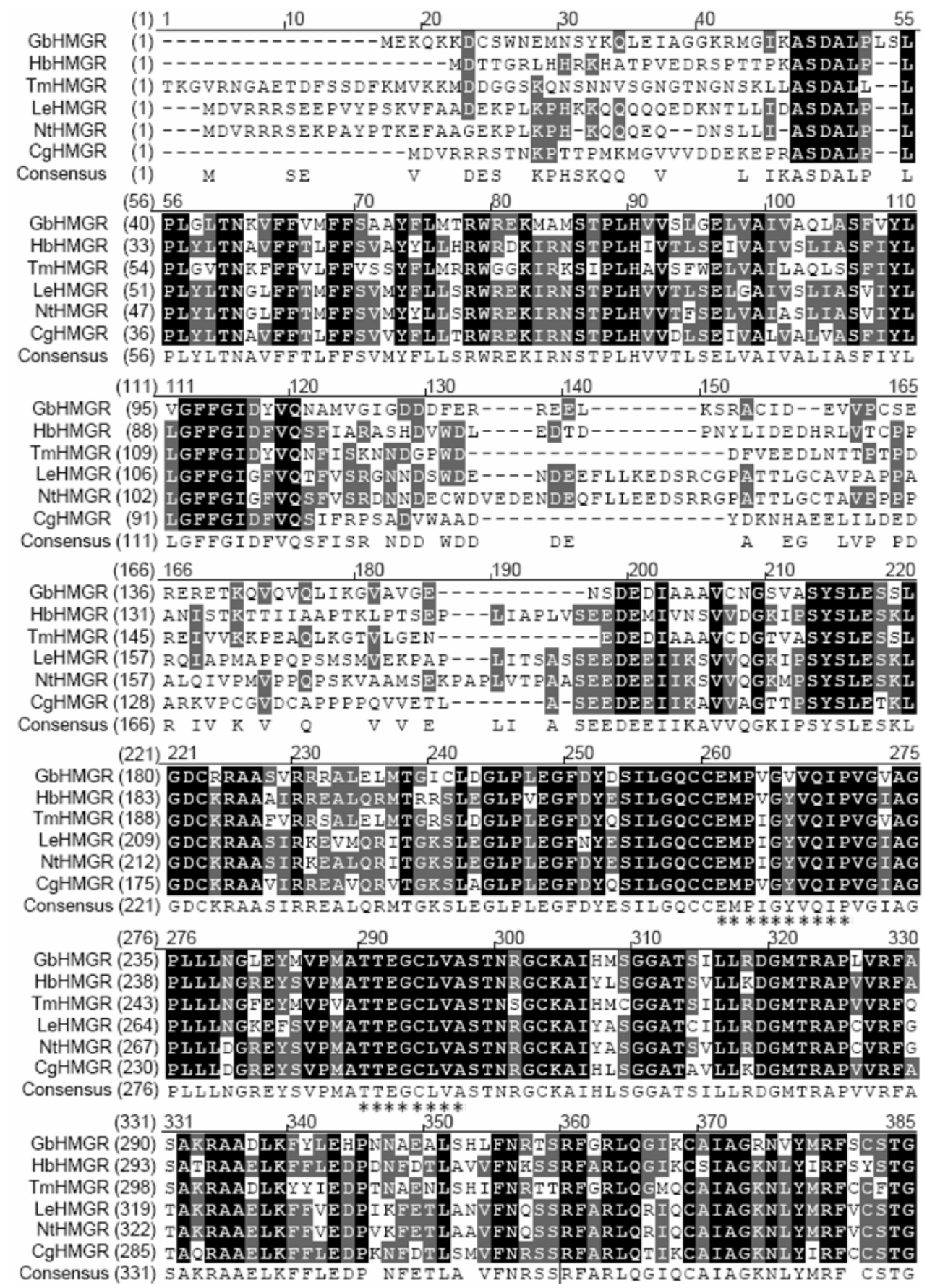

Fig. 2. Multiple alignment of the deduced amino acid sequences of CgHMGR and other plant HMGRs from Ginkgo biloba (accession no. AY741133), Taxus x media (accession no. AY277740), Hevea brasiliensis (accession no. AAU08214), Lycopersicon esculentum (accession no. AAB62581), Nicotiana tabacum (accession no. AAL54879). The completely identical amino acids are indicated with white foreground and black background. Conserved amino acids are denoted with white foreground and grey background. Non-similar amino acids are indicated with black foreground and white background. Two putative HMG-CoA-binding sites (EMPIGYVQIP and TTEGCLVA) and two NADP(H)-binding sites (DAMGMNM and GTVGGGT) are indicated with asterisks.

from some higher plant species such as Cucumis melo (KatoEmori et al., 2001), Taxus x media (Liao et al., 2004), Ginkgo biloba (Shen et al., 2006) and Eucommia ulmoides (Jiang et al., 2006) because of its importance for primary and secondary metabolite biosynthesis. Total RNA extracted from hazel leaves, and the degenerate primers (HMGRF and HMGRR) were used to amplify a 458-bp product by RT-PCR A BLASTn search revealed that the obtained fragment had high 


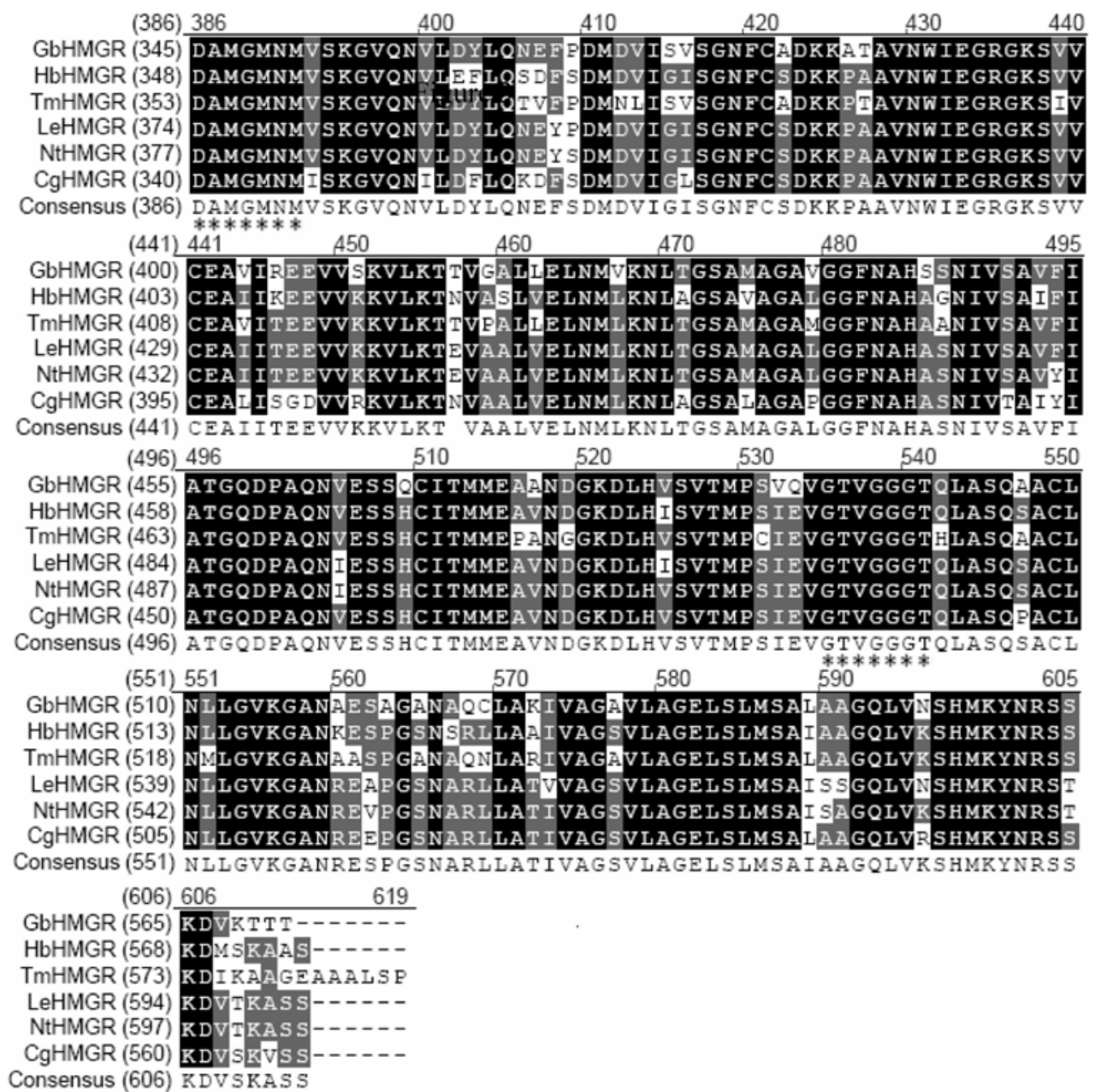

Fig. 2. Continued.

homology with $H M G R$ genes from other plant species. Two pairs of gene-specific primers were then designed and synthesized for the 3' RACE and 5' RACE based on the obtained fragment. By using the above mentioned methods, the full-length cDNA sequence of $C g H M G R$ was deduced, amplified and subsequently confirmed by sequencing. The full-length cDNA was $2064 \mathrm{bp}$ with 5' and 3' untranslated regions (UTR) and a polyA tail. The ORF search result showed that $C g H M G R$ contained a 1704 bp-ORF encoding a 567-amino-acid protein.

Characterization of the deduced CgHMGR protein. The predicted CgHMGR protein had a molecular mass of 60.83 $\mathrm{kDa}$ and a theoretical $\mathrm{pI}$ value of 6.43 (http://cn.expasy.org/ tools/protparam.html), which was very similar to the previously reported G. biloba HMGR (Shen et al., 2006). Protein-Protein BLAST and multiple alignment analysis showed the deduced CgHMGR amino acid sequence had high homology with HMGR sequences from other plant species, such as Hevea brasiliensis (80\%), Camptotheca acuminate (77\%), Nicotiana tabacum (73\%), Lycopersicon esculentum (72\%), Ginkgo biloba (70\%), Taxus $x$ media (68\%), respectively, suggesting that CgHMGR belonged to the HMGR family.

It was well known that HMGRs were classified into two distinct classes: eukaryotic HMGRs (class I) and prokaryotic HMGRs (class II) (Bochar et al., 1999). The membrane domains of plant HMGRs (class I) contained two membranespanning helices (Istvan et al., 2000). Two transmembrane regions of CgHMGR were predicted by TMHMM 2.0 (http:// www.cbs.dtu.dk/services/TMHMM-2.0/), revealing that one region was located between Pro34 (P) and Leu56 (L) and the other was located between Ile77 (I) and Val99 (V) along the polypeptide chain. The amino acid multiple alignment analysis showed that the N-terminal end of CgHMGR was quite diverse in both length and composition, and the C-terminal catalytic domain of CgHMGR had high similarity when compared with other plant HMGRs (Fig. 2). Plant HMGR comprised two HMG-CoA binding motifs (EMPIGYVQIP and TTEGCLVA) and two NADPH-binding motifs (DAMGMNM and GTVGGGT) (Kato-Emori et al., 2001; Liao et al., 2004; Jiang et al., 2006; Shen et al., 2006). The highest homology regions appeared around the substrate- 


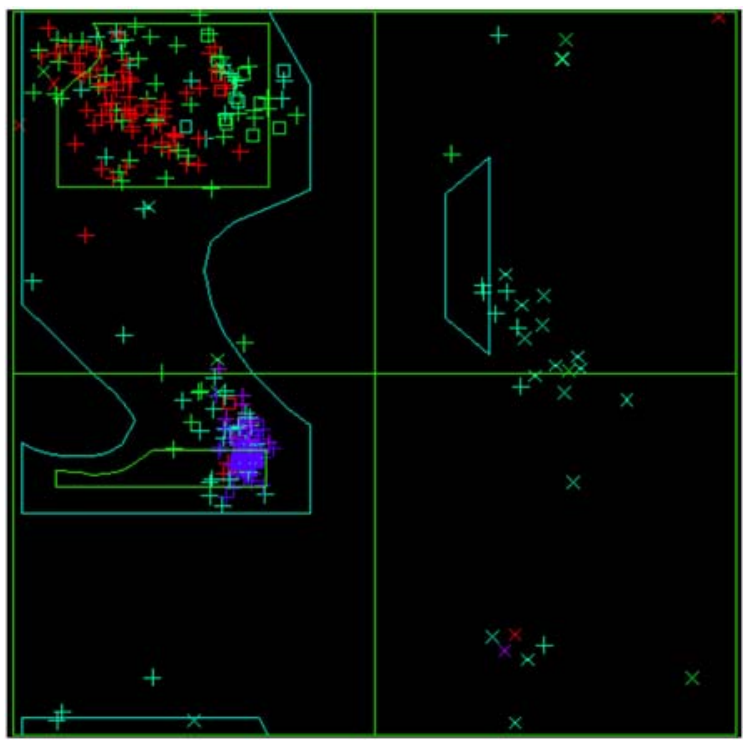

Fig. 3. Ramachandran plot of CgHMGR. Blue, red and green mean helix, strand and turn and random coil, respectively.

binding sites (Fig. 2). The sequence analysis revealed that the functional motifs of CgHMGR were very similar to those of other plant HMGRs.

The result of a ramachandran plot was shown in Fig. 3. The ramachandran plot showed that all the main chain conformational angles fell into core and allowed regions. Therefore, the structure has good main chain stereochemistry. The 3-D structure of CgHMGR was analyzed by SwissModeling on the basis of the Homo sapiens HMGR crystal structure. Comparison of CgHMGR protein with human HMGR revealed $56.4 \%$ identity in 426 aa overlap, which was good for homology-based modeling. The result showed that the catalytic domain of CgHMGR consisted of three domains including the small helical N-terminal domain, the large Ldomain containing two HMG-CoA-binding motifs and a $\operatorname{NADP}(\mathrm{H})$-binding motif and the smallest S-domain harboring a NADP(H)-binding motif (Fig. 4). The 3-D structure of CgHMGR strongly resembled human HMGR, indicating that they had potential catalytic similarities.

Southern blot analysis. In plants, HMGR is encoded by two genes in Arabidopsis thaliana (Enjuto et al., 1994), three genes in potato (Korth et al., 1997) and Hevea rasiliensis (Chye et al., 1992), and more genes in tomato (Denbow et al., 1996), wheat (Aoyagi et al., 1993) and mulberry (Jain et al., 2000). To investigate the genomic organization of $C g H M G R$ in hazel, Southern blot analysis was carried out by digesting the hazel genomic DNA with three different restriction enzymes (BglII, EcoRI, and HindIII) respectively, followed by hybridization with the 682-bp probe generated by PCR using the coding sequence of $C g H M G R$ as template. The result showed that at least three hybridizing bands were present in

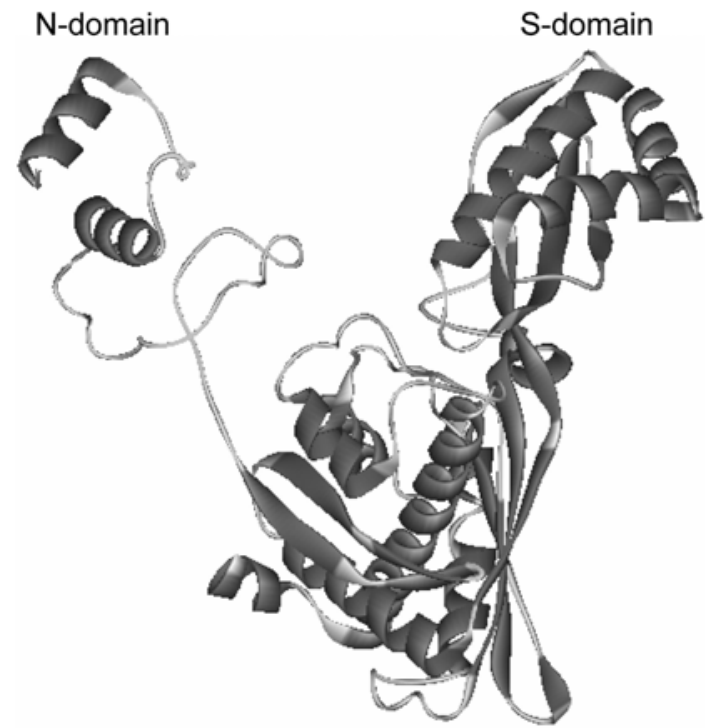

L-domain

Fig. 4. The predicted 3-D structure of CgHMGR. The helical Nterminal $\mathrm{N}$-domain, the large central L-domain and the small helical S-domain are indicated.

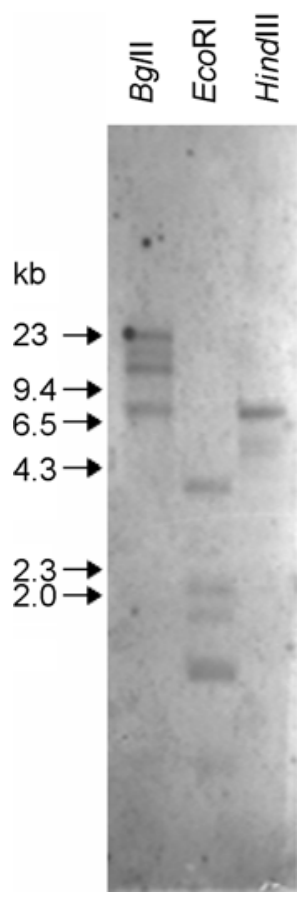

Fig. 5. Southern blot analysis. Genomic DNA of $C g H M G R$ was digested with $B g l I I, E c o$ RI and HindIII respectively, followed by hybridization with the biotin-labeled $C g H M G R$ fragment as the probe.

each lane under high stringency conditions (Fig. 5), indicating that $C g H M G R$ belonged to a small gene family, like the counterparts from some other tree species such as Taxus $x$ media and G. biloba (Liao et al., 2004; Shen et al., 2006). 


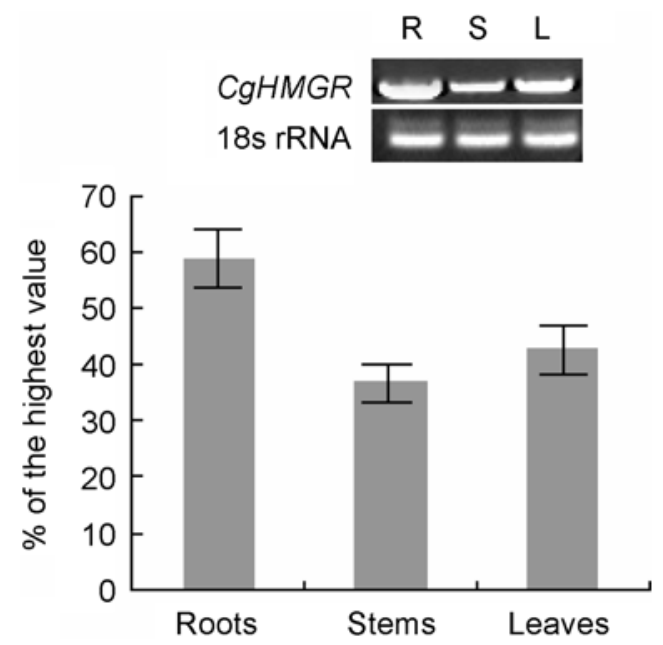

Fig. 6. Expression profile of $C g H M G R$ in different tissues of $C$. avellana. Total RNA was extracted from roots, stems and leaves respectively, and subjected to RT-PCR analysis. The 18S rRNA gene was used as the control for the normalization of RNA loading amount in RT-PCR reaction. The experiment was repeated three times.

\section{Expression profile of $\boldsymbol{C g H M G R}$ in different tissues of $\boldsymbol{C}$.} avellana. To investigate the expression pattern of $\mathrm{CgHMGR}$ in different tissues, total RNA was isolated from roots, stems and leaves respectively, and subjected to RT-PCR analysis. The result showed that $C g H M G R$ constitutively expressed in all tested tissues but at different levels with the highest expression in roots, followed by in leaves and stems (Fig. 6), similar to that reported in Ginkgo biloba (Shen et al., 2006). It was earlier reported that the content of taxol was the highest in roots (Liu et al., 2001), which was consistent with the expression pattern of $C g H M G R$ gene.

Many studies revealed that taxane production could be induced by various elicitors, such as methyl jasmonate (MeJA) in Taxus and hazel (Yukimune et al., 1996; Baebler et al., 2002; Bestoso et al., 2006). However, little was known about the expression profiles of genes involved in taxol biosynthetic pathway under elictor treatments. Therefore, it is worthwhile studying expression patterns of genes in taxol biosynthesis under various treatments including MeJA, which will be helpful to uncover molecular induction mechanism for further improving taxol biosynthesis in hazel. Semi-quantitative RT-PCR was performed to study the expression of $C g H M G R$ in response to MeJA. When treated with $2 \mathrm{mM}$ MeJA, the expression of $C g H M G R$ increased gradually within $48 \mathrm{~h}$, reached the highest level after $72 \mathrm{~h}$ and maintained the level thereafter (Fig. 7), demonstrating that the expression of CgHMGR could be induced by MeJA. This result suggests that MeJA treatment might be an effective approach to induce higher production of taxol from hazel.

Confirmation of $\boldsymbol{C g H M G R}$ function in $\boldsymbol{E}$. coli. E. coil could not synthesize carotenoids because of lacking of carotenogenic

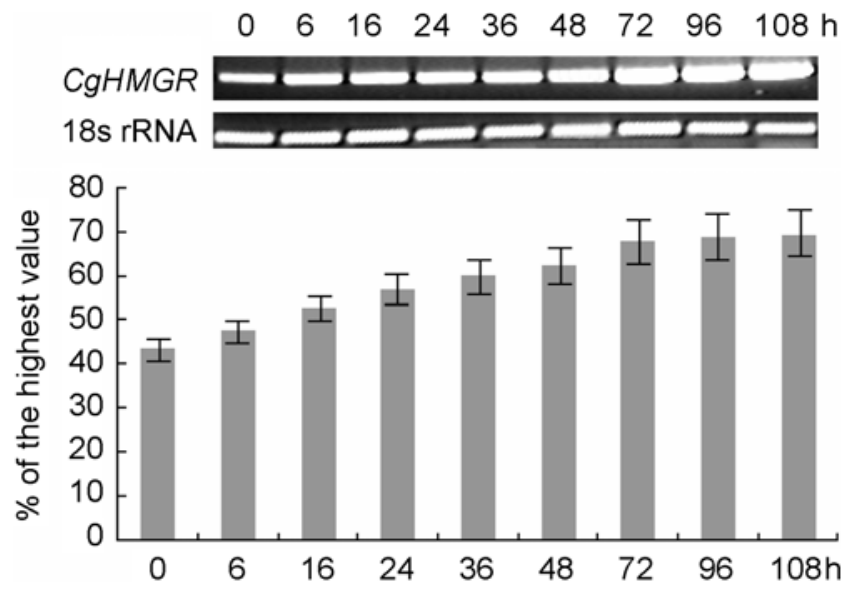

Fig. 7. Expression profile of $C g H M G R$ under $2 \mathrm{mM}$ methyl jasmonate (MeJA) induction treatment. RT-PCR analysis is performed by using total RNA isolated from treated leaves at different time points $(0,6,16,24,36,48,72,96$, and $108 \mathrm{~h})$. The $18 \mathrm{~S}$ rRNA gene was used as the loading control. The experiment was repeated three times.

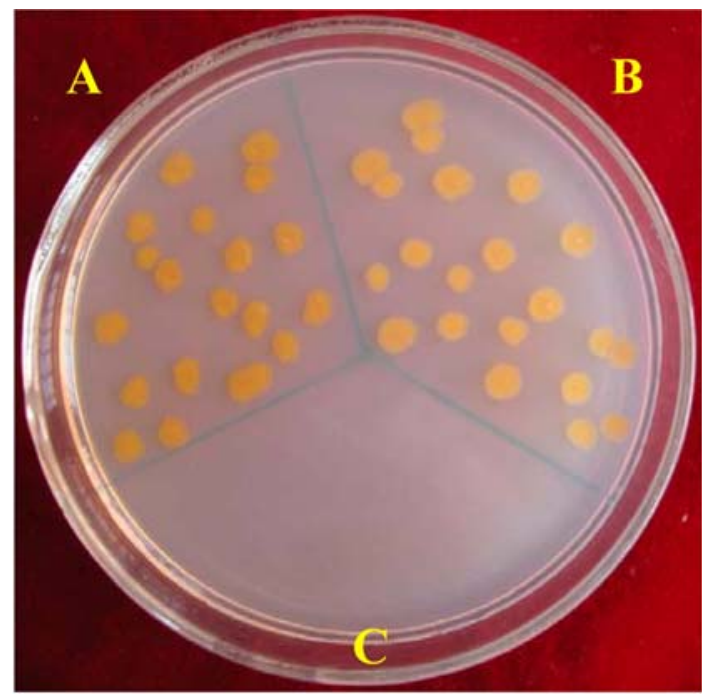

Fig. 8. Functional demonstration of CgHMGR in E. coli. The $E$. coli strain TOP $10 \mathrm{~F}^{\prime}$ was respectively transformed with pAC-BETA and pTrc-CgHMGR harboring $C g H M G R$ gene (A), pAC-BETA and $\mathrm{pTrc}(\mathrm{B})$, and pAC-BETA (C).

genes. However, E. coli introduced with foreign carotenogenic genes clusters had the ability to produce carotenoids, and transformed bacteria, owing to accumulating carotenoid pigments, could act as a visible marker for providing an easily screenable phenotype (Matthews and Wurtzel, 2000).

To test if CgHMGR encoded the anticipated functional protein, the plasmids pAC-BETA and pTrc-CgHMGR were co-transformed into $E$. coli TOP10 F'. The result showed that E. coli TOP10 F' containing pTrc-CgHMGR and pAC-BETA accumulated significantly higher saffron yellow $\beta$-carotene than the control with the empty vector pTrc and pAC-BETA 
(Fig. 8), demonstrating that CgHMGR could accelerate the accumulation of $\beta$-carotene. The E. coli TOP10 F' harboring single vector pAC-BETA could not grow on LB medium containing ampicillin and chloramphenicol due to the lack of ampicillin resistance gene. Since the precursors of $\beta$-carotene (tetraterpenes) and taxol (diterpenes) are biosynthesized through the same pathway (Eisenreich et al., 1998), it can be expected that CgHMGR helps to accelerate the accumulation of taxol in hazel. In fact, it has been reported that amorphadiene production was improved by $50 \%$ through transferring HMGR gene into engineered yeast (Ro et al., 2006).

In summary, we have successfully cloned and characterized a functional gene encoding 3-hydroxy-3-methylglutaryl-CoA reductase (HMGR) involved in the biosynthesis of taxol from C. avellana. Multiple alignments showed that the deduced CgHMGR had high identity to other plant HMGRs, and contained all conserved substrate-binding motifs of HMGRs. The three dimensional model of CgHMGR represented a typical spatial structure of HMGRs. Color complementation assay further confirmed that CgHMGR encoded a functional protein and played an important role in promoting $\beta$-carotene pathway flux. The cloning and characterization of $\mathrm{CgHMGR}$ will be helpful to understand the taxol biosynthesis in $C$. avellana at molecular level. Intensive studies, such as genetic transformation of $C g H M G R$ gene into hazel, are undergoing in order to determine its potential role in improving the production of taxol in hazel.

Acknowledgments The authors would like to acknowledge Drs. Shawn A. Mehlenbacher and Bruce R. Bartlett (Oregon State University, USA) for providing the hazel seeds and seedlings. This work was financially supported by the China National High-tech "863" Program and Shanghai Science and Technology Committee.

\section{References}

Aoyagi, K., Beyou, A., Moon, K., Fang, L. and Ulrich, T. (1993) Isolation and characterization of cDNAs encoding wheat 3hydroxy-3-methylglutaryl coenzyme A reductase. Plant Physiol. 102, 623-628.

Baebler, S., Camloh, M., Kovac, M., Ravnikar, M. and Zel, J. (2002) Jasmonic acid stimulates taxane production in cell suspension culture of yew (Taxus x media). Planta Med. 68, 475-476.

Boone, R. B., Hoffman, A., Daley, L. and Arbogast, B. (2000) How Taxol was found in hazelnut trees. Australian Nutgrower. 14, 36.

Bestoso, F., Ottaggio, L., Armirotti, A., Balbi, A., Damonte, G., Degan, P., Mazzei, M., Cavalli, F., Ledda, B. and Miele, M. (2006) In vitro cell cultures obtained from different explants of Corylus avellana produce Taxol and taxanes. BMC Biotechnol. 6, 45. doi:10.1186/1472-6750-6-45.

Bochar, D. A., Stauffacher, C. V. and Rodwell, V. W. (1999) Sequence comparisons reveal two classes of 3-hydroxy-3methylglutaryl coenzyme A reductase. Mol. Genet. Metab. 66, 122-127.

Chappell, J. (1995) The biochemistry and molecular biology of isoprenoid metabolism. Plant Physiol. 107, 1-6.

Chye, M. L., Tan, C. T. and Chua, N. H. (1992) Three genes encode 3-hydroxy -3-methylglutaryl coenzyme A reductase in Hevea brasiliensis: $h m g 1$ and $h m g 3$ are differentially expressed. Plant Mol. Biol. 19, 473-484.

Denbow, C. J., Lang, S. and Cramer, C. L. (1996) The N-terminal domain of tomato 3-hydroxy-3-methylglutaryl coenzyme A reductase. J. Biol. Chem. 271, 9710-9715.

Enjuto, M., Balcells, L., Campos, N., Caelles, C., Arro, M. and Boronat, A. (1994) Arabidopsis thaliana contains two differentially expressed 3-hydroxy-3-methylglutaryl-CoA reductase genes, which encode microsomal forms of the enzyme. Proc. Natl. Acad. Sci. USA 91, 927-931.

Eisenreich, W., Menhard, B., Hylands, P. J., Zenk, M. H. and Bacher, A. (1996) Studies on the biosynthesis of taxol: the taxane carbon skeleton is not of mevalonoid origin. Proc. Natl. Acad. Sci. USA 93, 6431-6436.

Eisenreich, W., Schwarz, M., Cartayrade, A., Arigoni, D., Zenk, M. H. and Bacher, A. (1998) The deoxyxylulose phosphate pathway of terpenoid biosynthesis in plants and microorganisms. Chem. Biol. 5, 221-R233.

Hoffman, A., Khan, W., Worapong, J., Strobel, G., Griffin, D., Arbogast, B., Barofsky, D., Boone, R. B., Ning, L., Zheng, P. and Daley, L. (1998) Bioprospecting for Taxol in angiosperm plant extracts. Spectroscopy 13, 22-32.

Istvan, E. S., Palnitkar, M., Buchanan, S. K. and Deisenhofer, J. (2000) Crystal structure of the catalytic portion of human HMGCoA reductase: insights into regulation of activity and catalysis. EMBO J. 19, 819-830.

Jiang, J. H., Kai, G. Y., Cao, X. Y., Chen, F. M., He, D. N. and Liu, Q. (2006) Molecular cloning of a HMG-CoA reductase gene from Eucommia ulmoides Oliver. Biosci Rep. 26, 171-181.

Jaakola, L., Pirttila, A. M., Halonen, M. and Hohtola, A. (2001) Isolation of high quality RNA from bilberry (Vaccinium myrtillus L.) fruit. Mol. Biotechnol. 19, 201-203.

Jain, A. K., Vincent, R. M. and Nessler, C. L. (2000) Molecular characterization of a hydroxymethylglutaryl-CoA reductase gene from mulberry (Morus alba L.). Plant Mol. Biol. 42, 559-569.

Jennewein, S., Wildung, M. R., Chau, M., Walker, K. and Croteau, R. (2004) Random sequencing of an induced Taxus cell cDNA library for identification of clones involved in Taxol biosynthesis. Proc. Natl. Acad. Sci. USA 101, 9149-9154.

Kato-Emori, S., Higashi, K., Hosoya, K., Kobayashi, T. and Ezura, H. (2001) Cloning and characterization of the gene encoding 3hydroxy-3-methylglutaryl coenzyme A reductase in melon (Cucumis melo L. reticulatus). Mol. Genet. Genomics 265, 135142.

Korth, K. L., Stemer, B. A., Bhattacharyya, M. K. and Dixon, R. A. (1997) HMG-CoA reductase gene families that differentially accumulate transcripts in potato tubers are developmentally expressed in floral tissues. Plant Mol. Biol. 33, 545-551.

Laule, O., Fürholz, A., Chang, H. S., Zhu, T., Wang, X., Heifetz, P. B., Gruissem, W. and Lange, B. M. (2003) Crosstalk between cytosolic and plastidial pathways of isoprenoid biosynthesis in Arabidopsis thaliana. Proc. Natl. Acad. Sci. USA 100, 6866-6871.

Lansing, A., Haertel, M., Gordon, M. and Floss, H. G. (1991) Biosynthetic studies on taxol. Planta Med. 57, 83.

Liao, Z. H., Tan, Q. M., Chai, Y. R., Zuo, K. J., Chen, M., Gong, Y. F, Wang, P., Pi, Y., Tang, F., Sun, X. F. and Tang, K. X. (2004) Cloning and chracterisation of the gene encoding HMG-CoA 
reductase from Taxus media and its functional identification in yeast. Funct. Plant Biol. 31, 73-81.

Liu, G. M., Fang, W. S., Qian, J. F. and Lan, H. (2001) Distribution of paclitaxel and its congeners in Taxus mairei. Fitoterapia 72, 743746.

Murashige, T. and Skoog, F. (1962) A revised medium for rapid growth and bioassay with tobacco tissue cultures. Physiol. Plant. 15, 473-497.

Matthews, P. D. and Wurtzel, E. T. (2000) Metabolic engineering of carotenoid accumulation in Escherichia coli by modulation of the isoprenoid precursor pool with expression of deoxyxylulose phosphate synthase. Appl. Microbiol. Biotechnol. 53, 396-400.

Misawa, N., Satomi, Y., Kondo, K., Yokoyama, A., Kajiwara, S., Saito, T., Ohtani, T. and Miki, W. (1995) Structure and functional analysis of a marine bacterial carotenoid biosynthesis gene cluster and astaxanthin biosynthetic pathway proposed at the gene level. J. Bacteriol. 177, 6575-6584.

Palazon, J., Cusido, R. M., Bonfill, M., Morales, C. and Pinol, M. T. (2003) Inhibition of paclitaxel and baccatin III accumulation by mevinolin and fosmidomycin in suspension cultures of Taxus baccata. J. Biotechnol. 101, 157-163.

Paterson, A. H., Curt, L. B. and Wendel, J. F. (1993) A rapid method for extraction of cotton (Gossypium ssp.) genomic DNA suitable for RFLP and PCR analysis. Plant Mol. Biol. Rep. 11, 122-127.

Rohmer, M., Knani, M., Simonin, P., Sutter, B. and Sahm, H. (1993) Isoprenoid biosynthesis in bacteria: a novel pathway for the early steps leading to isopentenyl diphosphate. Biochem. J. 295, 517-
524.

Ro, D. K., Paradise, E. M., Ouellet, M., Fisher, K. J., Newman, K. L., Ndungu, J. M., Ho, K. A., Eachus, R. A., Ham, T. S., Kirby, J., Chang, M. C., Withers, S. T., Shiba, Y., Sarpong, R. and Keasling, J. D. (2006) Production of the antimalarial drug precursor artemisinic acid in engineered yeast. Nature 440, 940-943.

Service, R. F. (2000) Hazel trees offer new source of cancer drug. Science 288, 27-28.

Schwede, T., Kopp, J., Guex, N. and Peitsch, M. C. (2003) SWISSMODEL: an automated protein homology-modeling server. Nucleic Acids Res. 31, 3381-3385.

Shen, G. A., Pang, Y. Z., Wu, W. S., Liao, Z. H., Zhao, L. X., Sun, X. F. and Tang, K. X. (2006) Cloning and characterization of a rootspecific expressing gene encoding 3-hydroxy-3-methylglutaryl coenzyme a reductase from Ginkgo biloba. Mol. Biol. Rep. 33, 117-127.

Wani, M. C., Taylor, H. L., Wall, M. E., Coggon, P. and McPhail, A. (1971) Plant antitumor agents. VI. The isolation and structure of Taxol, a novel antileukemic and antitumor agent from Taxus brevifolia. J. Am. Chem. Soc. 93, 2325-2327.

Yukimune, Y., Tabata, H., Higashi, Y. and Hara, Y. (1996) Methyl jasmonate induced overproduction of paclitaxel and baccatin III in Taxus cell suspension cultures. Nat. Biotechnol. 14, 1129-1132.

Zamir, L. O., Nedea, M. E. and Garneau, F. X. (1992) Biosynthetic building blocks of Taxus canadensis taxanes. Tetrahedron Lett. 33, 5235-5236. 